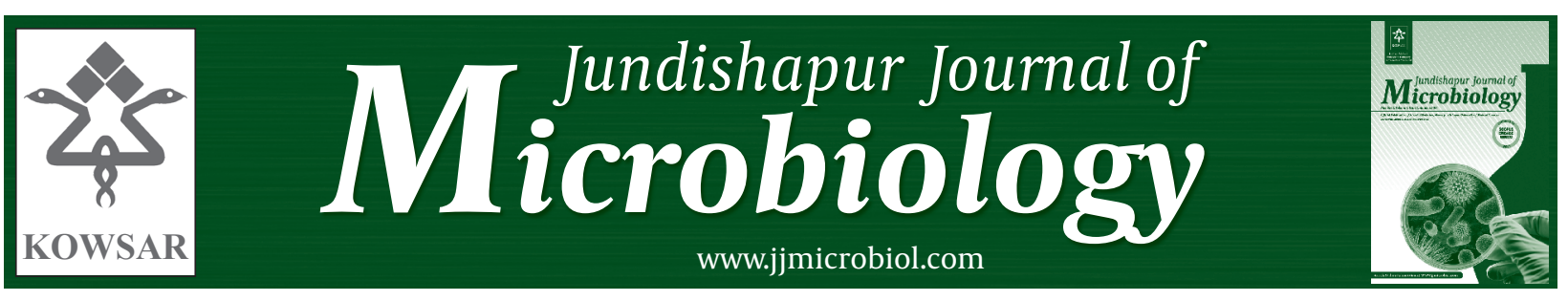

\title{
A Study of The Genetic Variability of Blastocystis hominis Isolates in Hamadan, West of Iran
}

\author{
Khosro Sardarian ${ }^{1^{*}}$, Mehrdad Hajilooi ${ }^{2}$, Amirhosein Maghsood ${ }^{1}$, Abbas Moghimbeigi ${ }^{3}$, Mo- \\ hamadyusef Alikhani ${ }^{4}$
}

${ }^{1}$ Department of Parasitology and Mycology, Hamadan University of Medical Sciences, Hamadan, IR Iran

2 Department of Immunology, Hamadan University of Medical Sciences, Hamadan, IR Iran

${ }^{3}$ Department of Epidemiology and Biostatistics, Hamadan University of Medical Sciences, Hamadan, IR Iran

${ }^{4}$ Department of Microbiology, School of Medicine, Hamadan University of Medical Sciences, Hamadan, IR Iran

\section{A R T I C L E I N F O}

Article type:

Original Article

Article history:

Received: 7 Jan 2011

Revised: 15 Mar 2012

Accepted: 4 Apr 2012

\section{Keywords:}

Blastocystis hominis

Genetic Variations

\begin{abstract}
A B S T R A C T
Background: Blastocystis is a common protozoan parasite in mammals, birds, amphibians, reptiles, fish, arthropods, and annelids. This parasite has some subtypes, which pathogenicity status of them still remained controversial. Some of Blastocystis subtypes are potentially pathogenic to human.

Objectives: This study has identified the B. hominis subtypes and their prevalence rates in Hamadan.

Patients and Methods: During two months of summer 2011, a total number of 250 human fecal samples referred for parasitology examination to Beasat Hospital and a few clinical laboratories of Hamadan city were collected. The samples were examined by direct method and formalin-ether. 41 samples exhibited positive results for B. hominis thereby were cultured in Locke-egg medium. After the growth and in order to genotype identification, B. hominis isolates were amplified by PCR, using seven pairs of sequencestagged site primers. .

Results: In this study, three subtypes of B. hominis consisted of one [SB83], two [SB340] and three [SB227] were identified. The most dominant genotype was SB83 with 56.1\% frequency. The prevalence rate of genotype SB227 and SB340 were $22 \%$ and 7.3\%, respectively. Coexistence of genotypes SB83 and SB227 was detected in $14.6 \%$ of positive cases.

Conclusions: This is the first study in Hamadan on genotyping of B. hominis, which may trigger other epidemiologic and zoonotic studies on different subtypes and hence control clinical manifestations of infection.
\end{abstract}

Published by Kowsar Corp, 2013. cc 3.0.

Implication for health policy/practice/research/medical education:

Blastocystis hominis is a common protozoan parasite in the human and many other animals intestine. the parasite pathogenicity is still controversial. A few studies have been conducted on prevalence of B.hominis subtypes in Iran. The results of present study improve our knowledge on B. hominis subtypes in Iran and therefore we can do more investigations on pathogenicity potential of these subtypes in the future.

- Please cite this paper as:

Sardarian K, Hajilooi M, Maghsood AH, Moghimbeigi A, Alikhani MY. A Study of The Genetic Variability of Blastocystis hominis Isolates in Hamadan, West of Iran. Jundishapour J Microbiol. 2013;6(1):11-5. DOI:10.5812/jjm.4171

\footnotetext{
${ }^{*}$ Corresponding author: Khosro Sardarian, Department of Parasitology and Mycology, Hamadan University of Medical Sciences, Hamadan, IR Iran. Tel: +988118380572, Fax:+98-8118383208, E-mail: Khsardarian@gmail.com

DOI: $10.5812 / j \mathrm{jm} .4171$

(C) 2013 Ahvaz Jundishapur University of Medical Sciences; Published by Kowsar Corp.

This is an Open Access article distributed under the terms of the Creative Commons Attribution License (http://creativecommons.org/licenses/by/3.0), which permits unrestricted use, distribution, and reproduction in any medium, provided the original work is properly cited.
} 


\section{Background}

Blastocystis hominis is the most common intestinal parasite in humans and many other animals (1). Infections with the organism are spread worldwide and it is often the most frequently isolated protozoan in parasitological surveys (2-4). In developing countries, B. hominis has higher prevalence $(30-50 \%)$ in comparison with developed countries $(1.5-10 \%)(5,6)$. The pathogenicity of $B$. hominis still has been debated. There are some reports supporting the pathogenic potential of this parasite (7). Clinical features related to $B$. hominis include nausea, anorexia, abdominal pain, flatulence, and acute or chronic diarrhea (8). However other studies state an opponent view point and it is believed that other factors probably are the causing agents of these symptoms (7, 9-11).

The studies have shown that $B$. hominis isolates of humans and animals display considerable genetic heterogeneity and have a few subtypes (12). It is supposed that the parasite has 13 subtypes (13), however, to date nine distinct subtypes have been identified (9), which some zoonotic subtypes have found in humans $(14,15)$. Based on morphologic and pathogenic potentials, there are nine different subtypes, each of them exhibits different features (16-18). Probably each subtype demonstrate its own pathogenicity (19); therefore it is necessary to know specific subtypes of each region.

\section{Objectives}

The aim of this study was to determine subtypes of $B$. hominis and relevant prevalence of each in Hamadan city, west of Iran.

\section{Patients and Methods}

\subsection{Samples}

Simple random sampling was applied in this study. Forty one samples of B. hominis were detected as positive that was on the basis of an expected prevalence of 37.1\% (20), with a maximum sampling error of 0.15 and a confidence interval (CI) of 95\%. During two months of summer 2011, a total number of 250 fecal samples were collected from the people referred for parasitological examination to Beasat Hospital and a few clinical laboratories of Hamadan city. The samples were transferred to the Parasitology Laboratory of Faculty of Medicine, Hamadan University of Medical Sciences. They were tested for the presence of B. hominis by formalin-ether method. To increase the accuracy, the samples were stained by iodine and trichrome techniques.

\subsection{Culture of Blastocystis Isolates}

After microscopic observation of the parasite in fecal samples, any debris was removed from positive samples by the use of centrifugation. The positive samples were cultured in Locke-egg (LE) medium and incubated at $37^{\circ} \mathrm{C}$ for 48-72 hours according to Clark and Diamond (21).

\subsection{Extraction of Genomic DNA}

Genomic DNA of each isolate was extracted by genomic DNA purification kit (Sinagen Co, Iran) according to the manufacturer's protocol.

\subsection{Genotyping}

To identify B. hominis genotypes, seven pairs of Sequences-tagged site (STS) primers [SB83, SB340, SB227, SB337, SB336, SB332, and SB155] were used with PCR technique (22) (Table 1). PCR was performed as following: DNA of 41 isolates was amplified by specific primers. The reaction was carried out within $50 \mu \mathrm{L}$ final volumes including the following materials: $10 \mu \mathrm{L}$ DNA, 5 PG of each pair primers, $2.5 \mathrm{mM} \mathrm{Cl}_{2} \mathrm{Mg}, 5 \mu \mathrm{l}$ PCR buffer $\mathrm{pH}=8.3$, and 0.5 UI Taq DNA polymerase [Bioprobe]. This combination was entered the cycle described as follows: denaturation at $94^{\circ} \mathrm{C}$ for three minutes, and 30 Cycles denaturation at $94^{\circ} \mathrm{C}$ for

\begin{tabular}{|c|c|c|c|}
\hline & Product Size, bp & Sequences of F and R Primers (5'-3') & GenBank Acc, No. \\
\hline \multirow[t]{2}{*}{ SB83 Sub I } & 351 & F:GAAGGACTCTCTGACGATGA & AF166086 \\
\hline & & R:GTCCAAATGAAAGGCAGC & \\
\hline \multirow[t]{2}{*}{ SB340 Sub II } & 704 & F:TGTTCTTGTGTCTTCTCAGCTC & AY048752 \\
\hline & & R:TTCTTTCACACTCCCGTCAT & \\
\hline \multirow[t]{2}{*}{ SB227 Sub III } & 526 & F:TAGGATTTGGTGTTTGGAGA & AF166088 \\
\hline & & R:TTAGAAGTGAAGGAGATGGAAG & \\
\hline \multirow[t]{2}{*}{ SB337 Sub IV } & 487 & F:GTCTTTCCCTGTCTATTCTTGCA & AY048750 \\
\hline & & R:AATTCGGTCTGCTTCTTCTG & \\
\hline \multirow[t]{2}{*}{ SB336 Sub V } & 317 & F:GTGGGTAGAGGAAGGAAAACA & AY048751 \\
\hline & & R:AGAACAAGTCGATGAAGTGAGAT & \\
\hline \multirow[t]{2}{*}{ SB332 Sub VI } & 338 & F:GCATCCAGACTACTATCAACATT & AF166091 \\
\hline & & R:CCATTTTCAGACAACCACTTA & \\
\hline \multirow[t]{2}{*}{ SB155 Sub VII } & 650 & F:ATCAGCCTACAATCTCCTC & AF166087 \\
\hline & & R:ATCGCCACTTCTCCAAT & \\
\hline
\end{tabular}


$30 \mathrm{sec}$, annealing at $56^{\circ} \mathrm{C}$ for $30 \mathrm{sec}$, extension at $72^{\circ} \mathrm{C}$ for $30 \mathrm{sec}$, and final extension at $72^{\circ} \mathrm{C}$ for five min. The product of PCR was flowed on 1.5\% agarose gel containing ethidium bromide with 100 bp DNA ladder.

\section{Results}

According to Table 2, the genotype SB83 was the most identified genotype representing $56.1 \%$ of isolates, followed by genotype SB227 [22\%], mixture of SB83 and SB227 genotypes [14.6\%], and genotype SB340 [7.3\%]. Other genotypes were not detected in this study. In serial order, subtypes SB83 and SB227 were the most frequent isolates in this research. The PCR amplification of $B$. hominis isolates with the primers SB83 [351 bp], SB340 [704 bp], and SB227 [526 bp] were shown in Figures 1-3.

\begin{tabular}{ll}
\hline \multicolumn{1}{|c}{ Table 1. Frequency of Different Genotypes of 41 Blastocystis hominis Isolates } \\
\hline & No. $(\%)$ \\
\hline $\mathbf{1}$ [SB83] & $23(56.1)$ \\
$\mathbf{2}[\mathrm{SB340}]$ & $3(7.3)$ \\
$\mathbf{3}[\mathrm{SB227}]$ & $9(22)$ \\
$\mathbf{1}$ [SB83] and 3 [SB227] & $6(14.6)$ \\
Other genotypes & $0(0)$ \\
Total & $41(100)$ \\
\hline
\end{tabular}

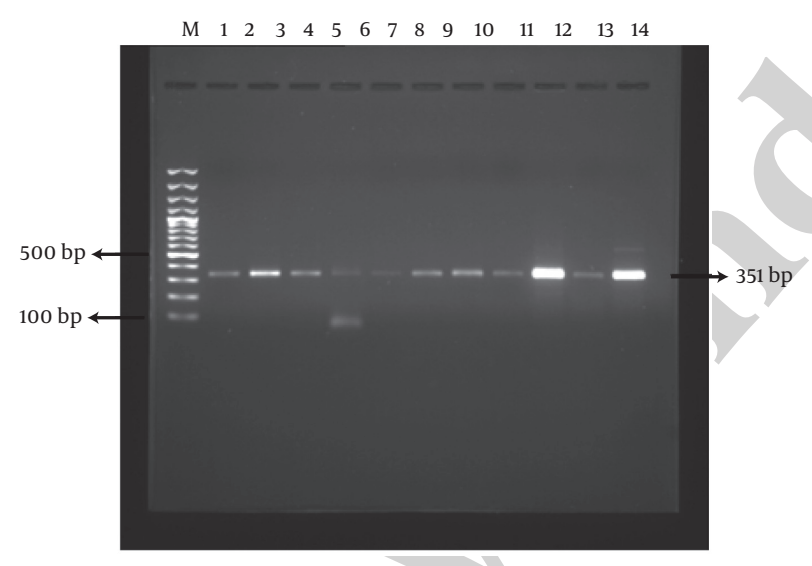

Figure 1. The PCR Amplification of Sb83 Genotype

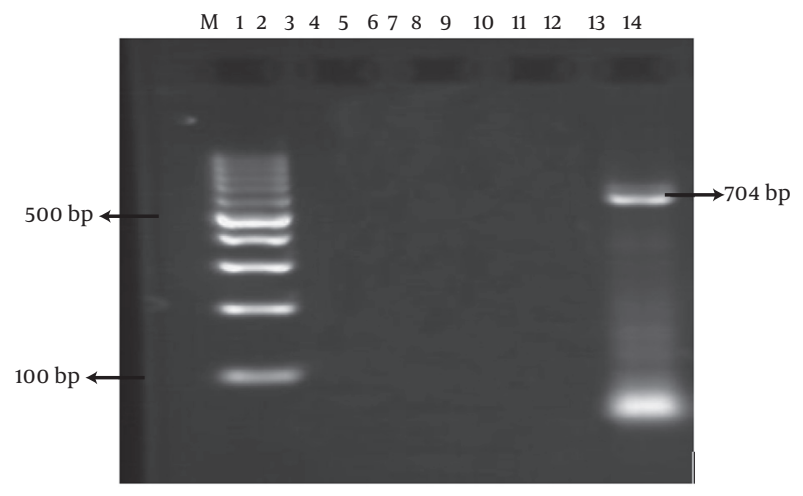

Figure 2. The PCR Amplification of Sb340 Genotype

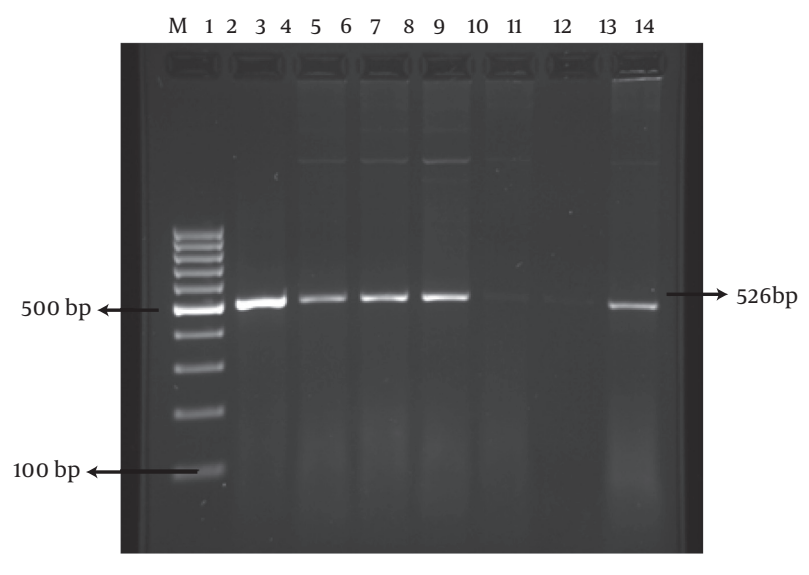

Figure 3. The PCR Amplification of Sb227 Genotype

\section{Discussion}

Some studies have been conducted on prevalence and pathogenesis of $B$. hominis in Iran. Prevalence rates of B.hominis have been reported from 0.08\% to 54.5\% (23-29). However, there are few studies with focus on the pathogenesis aspect of $B$. hominis $(25,27,30)$. In this study, the pathogenesis of $B$. hominis subtypes is not investigated but some differences in virulence between Blastocystis subtypes was shown $(9,20,31,32)$. In many studies, pathogenic potential of subtype 3 has been reported $(16,31,33-$ 35). Also, some investigations have demonstrated that other subtypes such as subtype 1 were associated with symptoms $(20,31,34,36)$.

Three genotypes were detected in this study including SB83, SB340, and SB227. The results are similar to some other studies performed worldwide $(14,15,21,36-38)$. The frequency of subtype SB83 was more than subtypes SB227 and SB340 that is similar to some other researches $(5,17$, 20). The subtypes SB337, SB336, SB332 and SB155 were not detected. In the current study, the most frequent subtype was SB83 that conforms to some other investigations (15, $27,39)$. In human isolates, the highest prevalence has been related to subtype SB227 and other subtypes have shown different prevalence rates $(9,20,21,37,39,40)$.

In human studies, mixed infections with subtypes SB227 and SB83, and with subtypes SB340 and SB337 were reported (41). This study showed that similar to some other studies (13), the subtype of SB227 exhibits the lowest prevalence rate in this region of Iran [3.7\%]. Furthermore, $14.6 \%$ of the persons were infected by genotypes SB83 and SB227, simultaneously. In some studies, the rate of mixed infections has been observed from 1.1 to $14.3(5,19,21,39)$. The frequency of mixed infections with subtypes SB83 and SB340 (5), with SB340 and SB227 (5), and with SB227 and SB336 (39) was low. Because of different growth rates of $B$. hominis subtypes in culture media, we may have ignored some mixed subtypes in infected patients. Thus, this could be a limitation for current research. Direct PCR method application on DNA obtained from stool samples is suggested (19). 
This is a novel study in this region of Iran, which can help the researchers to be aware of epidemiological patterns of this parasite. These data would trigger other epidemiologic and zoonotic studies on different subtypes and hence control clinical manifestations of infection.

\section{Acknowledgements}

We thank Miss Karimkhani for technical help.

\section{Financial Disclosure}

None Declared.

\section{Funding Support}

We thanks from Hamadan University of Medical Sciences for financial supporting.

\section{Authors' Contribution}

None declared.

\section{References}

1. Windsor JJ, Macfarlane L, Hughes-Thapa G, Jones SK, Whiteside TM. Incidence of Blastocystis hominis in faecal samples submitted for routine microbiological analysis. $\mathrm{Br} J$ Biomed Sci. 2002;59(3):154-7.

2. Boorom KF, Smith H, Nimri L, Viscogliosi E, Spanakos G, Parkar U, et al. Oh my aching gut: irritable bowel syndrome, Blastocystis, and asymptomatic infection. Parasit Vectors. 2008;1(1):40.

3. Chandramathi S, Suresh K, Kuppusamy UR. Elevated levels of urinary hyaluronidase in humans infected with intestinal parasites. Ann Trop Med Parasitol. 2010;104(5):449-52.

4. Roldan WH, Espinoza YA, Huapaya PE, Huiza AF, Sevilla CR, Jimenez S. Frequency of human toxocariasis in a rural population from Cajamarca, Peru determined by DOT-ELISA test. Rev Inst Med Trop Sao Paulo. 2009;51(2):67-71.

5. Li LH, Zhou XN, Du ZW, Wang XZ, Wang LB, Jiang JY, et al. Molecular epidemiology of human Blastocystis in a village in Yunnan province, China. Parasitol Int. 2007;56(4):281-6.

6. Vogelberg C, Stensvold CR, Monecke S, Ditzen A, Stopsack K, Heinrich-Grafe $U$, et al. Blastocystis sp. subtype 2 detection during recurrence of gastrointestinal and urticarial symptoms. Parasitol Int. 2010;59(3):469-71.

7. Ok UZ, Girginkardesler N, Balcioglu C, Ertan P, Pirildar T, Kilimcioglu AA. Effect of trimethoprim-sulfamethaxazole in Blastocystis hominis infection. Am J Gastroenterol. 1999;94(11):3245-7.

8. Sohail MR, Fischer PR. Blastocystis hominis and travelers. Travel Med Infect Dis. 2005;3(1):33-8.

9. Hussein EM, Hussein AM, Eida MM, Atwa MM. Pathophysiological variability of different genotypes of human Blastocystis hominis Egyptian isolates in experimentally infected rats. Parasitol Res. 2008;102(5):853-60.

10. Kaya S, Cetin ES, Aridogan BC, Arikan S, Demirci M. Pathogenicity of Blastocystis hominis, a clinical reevaluation. Turkiye Parazitol Derg. 2007;31(3):184-7.

11. Rossignol JF, Kabil SM, Said M, Samir H, Younis AM. Effect of nitazoxanide in persistent diarrhea and enteritis associated with Blastocystis hominis. Clin Gastroenterol Hepatol. 2005;3(10):987-91.

12. Stensvold CR, Arendrup MC, Jespersgaard C, Molbak K, Nielsen HV. Detecting Blastocystis using parasitologic and DNA-based methods: a comparative study. Diagn Microbiol Infect Dis. 2007;59(3):303-7.

13. Stensvold CR, Suresh GK, Tan KS, Thompson RC, Traub RJ, Viscogliosi E, et al. Terminology for Blastocystis subtypes-a consen- sus. Trends Parasitol. 2007;23(3):93-6.

14. Noel C, Dufernez F, Gerbod D, Edgcomb VP, Delgado-Viscogliosi P, Ho LC, et al. Molecular phylogenies of Blastocystis isolates from different hosts: implications for genetic diversity, identification of species, and zoonosis. J Clin Microbiol. 2005;43(1):348-55.

15. Yakoob J, Jafri W, Beg MA, Abbas Z, Naz S, Islam M, et al. Irritable bowel syndrome: is it associated with genotypes of Blastocystis hominis. Parasitol Res. 2010;106(5):1033-8.

16. Katsarou-Katsari A, Vassalos CM, Tzanetou K, Spanakos G, Papadopoulou C, Vakalis N. Acute urticaria associated with amoeboid forms of Blastocystis sp. subtype 3. Acta Derm Venereol. 2008;88(1):80-1.

17. Leelayoova S, Siripattanapipong S, Thathaisong U, Naaglor T, Taamasri P, Piyaraj P, et al. Drinking water: a possible source of Blastocystis spp. subtype 1 infection in schoolchildren of a rural community in central Thailand. Am J Trop Med Hyg. 2008;79(3):401-6.

18. Stensvold CR, Nielsen HV, Molbak K, Smith HV. Pursuing the clinical significance of Blastocystis--diagnostic limitations. Trends Parasitol. 2009;25(1):23-9.

19. Tan KS. New insights on classification, identification, and clinical relevance of Blastocystis spp. Clin Microbiol Rev. 2008;21(4):639-65.

20. Yan Y, Su S, Lai R, Liao H, Ye J, Li X, et al. Genetic variability of Blastocystis hominis isolates in China. Parasitol Res. 2006;99(5):597601.

21. Clark CG, Diamond LS. Methods for cultivation of luminal parasitic protists of clinical importance. Clin Microbiol Rev. 2002;15(3):329-41.

22. Yoshikawa H, Wu Z, Kimata I, Iseki M, Ali IK, Hossain MB, et al. Polymerase chain reaction-based genotype classification among human Blastocystis hominis populations isolated from different countries. Parasitol Res. 2004;92(1):22-9.

23. Arani AS, Alaghehbandan R, Akhlaghi L, Shahi M, Lari AR. Prevalence of intestinal parasites in a population in south of Tehran, Iran. Rev Inst Med Trop Sao Paulo. 2008;50(3):145-9.

24. Haghighi A, Khorashad AS, Nazemalhosseini Mojarad E, Kazemi B, Rostami Nejad M, Rasti S. Frequency of enteric protozoan parasites among patients with gastrointestinal complaints in medical centers of Zahedan, Iran. Trans $R$ Soc Trop Med Hyg. 2009;103(5):452-4.

25. Motazedian H, Ghasemi H, Sadjjadi SM. Genomic diversity of Blastocystis hominis from patients in southern Iran. Ann Trop Med Parasitol. 2008;102(1):85-8.

26. Nasiri V, Esmailnia K, Karim G, Nasir M, Akhavan O. Intestinal parasitic infections among inhabitants of Karaj City, Tehran province, Iran in 2006-2008. Korean J Parasitol. 2009;47(3):265-8.

27. Rostami Nejad M, Nazemalhosseini Mojarad E, Dabiri H, Nochi Z, Pourhoseingholi MA, Sahebekhtiari N, et al. A case-control study of Blastocystis hominis among Iranian population. East Afr J Public Health. 2010;7(1):101-4.

28. Sharif M, Daryani A, Asgarian F, Nasrolahei M. Intestinal parasitic infections among intellectual disability children in rehabilitation centers of northern Iran. Res Dev Disabil. 2010;31(4):924-8.

29. Taherkhani H, Sardarian K, Semnani S, Roshandel G. Blastocystosis in Iran: Epidemiological characteristics and Clinical manifestations. JClin Diagn Res. 2008;2:969-72.

30. Sardarian K, Taherkhani H. Blastocystosis Pathogenecity With Methronidazole Effect Approach.J Guilan Univ Med Sci. 2002.

31. Jones MS, Whipps CM, Ganac RD, Hudson NR, Boorom K. Association of Blastocystis subtype 3 and 1 with patients from an Oregon community presenting with chronic gastrointestinal illness. Parasitol Res. 2009;104(2):341-5.

32. Mirza H, Tan KS. Blastocystis exhibits inter- and intra-subtype variation in cysteine protease activity. Parasitol Res. 2009;104(2):355-61.

33. Dogruman-Al F, Kustimur S, Yoshikawa H, Tuncer C, Simsek Z, Tanyuksel M, et al. Blastocystis subtypes in irritable bowel syndrome and inflammatory bowel disease in Ankara, Turkey. Mem Inst Oswaldo Cruz. 2009;104(5):724-7.

34. Nagel R, Cuttell L, Stensvold CR, Mills PC, Bielefeldt-Ohmann H, Traub RJ. Blastocystis Subtypes in Symptomatic and Asymptomatic Family Members and Pets and Response to Therapy. Intern 
Med J. 2011.

35. Tan TC, Suresh KG, Smith HV. Phenotypic and genotypic characterisation of Blastocystis hominis isolates implicates subtype 3 as a subtype with pathogenic potential. Parasitol Res. 2008;104(1):85-93.

36. Kaneda Y, Horiki N, Cheng XJ, Fujita Y, Maruyama M, Tachibana H. Ribodemes of Blastocystis hominis isolated in Japan. Am J Trop Med Hyg. 2001;65(4):393-6.

37. Stensvold CR, Alfellani MA, Norskov-Lauritsen S, Prip K, Victory EL, Maddox C, et al. Subtype distribution of Blastocystis isolates from synanthropic and zoo animals and identification of a new subtype. Int J Parasitol. 2009;39(4):473-9.

38. Sun T, Katz S, Tanenbaum B, Schenone C. Questionable clinical significance of Blastocystis hominis infection. Am J Gastroenterol. 1989;84(12):1543-7.

39. Yoshikawa H, Wu Z, Pandey K, Pandey BD, Sherchand JB, Yanagi T, et al. Molecular characterization of Blastocystis isolates from children and rhesus monkeys in Kathmandu, Nepal. Vet Parasitol. 2009;160(3-4):295-300.

40. Dominguez-Marquez MV, Guna R, Munoz C, Gomez-Munoz MT, Borras R. High prevalence of subtype 4 among isolates of Blastocystis hominis from symptomatic patients of a health district of Valencia (Spain). Parasitol Res. 2009;105(4):949-55.

41. Ozyurt M, Kurt O, Molbak K, Nielsen HV, Haznedaroglu T, Stensvold CR. Molecular epidemiology of Blastocystis infections in Turkey. Parasitol Int. 2008;57(3):300-6. 